\title{
The use of 3D ultrasound to investigate fetal bone development
}

\author{
Pamela A. Mahon, Cyrus Cooper, Sarah R. Crozier and Keith M. Godfrey \\ MRC Epidemiology Resource Centre, University of Southampton, Southampton General Hospital, Tremona Road, \\ Southampton, Hampshire, SO16 6YD \\ E-mail:pam@mrc.soton.ac.uk
}

\begin{abstract}
Epidemiological studies suggest impaired fetal skeletal development has lifelong consequences for bone health. To examine the feasibility of using 3-dimensional ultrasound (3DUS) to investigate influences on fetal femur development, we obtained volume datasets of the uppermost fetal thigh at 19 and 34 weeks gestation in 517 women in a population-based survey of maternal nutrition. In addition to the standard measure of femur length, we derived femoral cross-sectional areas and volume from the volume datasets.

Coefficients of variation for intra-operator variability in femur length were $0.6 \%$ at 19 weeks and $0.4 \%$ at 34 weeks; corresponding coefficients of variation for distal femoral cross-sectional area were $4.4 \%$ at 19 weeks and $3.2 \%$ at 34 weeks, showing greater measurement variability with a more complex technique. Intra-operator variability for femur volume measurement triplets at 19 and 34 weeks was $3.4 \%$ and $1.7 \%$, respectively.

The coefficients of variation of replicate measurements were compared with the between-subjects variation as a measure of the biological variability between fetuses: at 19 weeks between-subjects variation was $7.2 \%$ for femur length, $19.6 \%$ for distal cross-sectional area and $19.9 \%$ for femur volume. These results show a wide range of variation between subjects, which is substantially greater than the intra-operator variability. This suggests that the measurements of fetal femur size and volume are reproducible and can be used to examine biological differences between subjects, and we found that femoral volume was greater in male fetuses at 19 weeks gestation. Thus 3DUS presents a useful technique for assessing fetal skeletal development in cohort studies.
\end{abstract}

\section{BACKGROUND}

In the last 20 years evidence has accrued that an adverse intrauterine environment may increase the risk of a number of common chronic diseases in later life, including osteoporotic fractures (1-3). Development is particularly 'plastic' during fetal life and it is now known that variations in the intra-uterine environment result in fetal adaptations that can have long-term consequences $(4,5)$. Alterations in the supply of nutrients to the fetus can permanently change the body's structure, function and expectation of life after birth, which can programme the individual to be predisposed to illhealth.

An infant's bone development, bone size, density and strength, can all be influenced or limited by the nutritional state of the mother, acting together with recently identified genetic influences $(5,6)$, and epidemiological studies suggest that weight and body composition in infancy influence the risk of osteoporosis in adult life $(2,7,8)$. Additionally, maternal thinness, smoking and vitamin $\mathrm{D}$ insufficiency have been linked with impaired bone mineralisation in the offspring $(9,10)$. Many studies have explored aspects of developmental origins of cardiovascular and metabolic disease, but to date few have assessed fetal musculoskeletal development in the same depth, especially using ultrasound as the research tool.
Ultrasound is the imaging modality most often used to screen for anomalies in the growing human fetus, as it is a non-invasive technology. Since its inception over 50 years ago, medical ultrasound has evolved dramatically. Over $25 \%$ of all medical imaging studies worldwide are ultrasound examinations, demonstrating its diversity of use and importance (11). An additional component is the development of three-dimensional ultrasound, which has led to advances in the field of prenatal diagnosis. Developments in computing and transducer materials have made three and fourdimensional ultrasound possible (3D and 4D hereafter), with improved image quality and data storage. It is now possible to "map" patients' anatomy so that structural relationships can be highlighted (12). This 3D mapping has become commonplace offering safe, early fetal imaging, generated by machines that produce high resolution, noise-free, real-time, dynamic images. Furthermore, ultrasound is affordable and produces images that can be manipulated and viewed without the subject being present. To date, it has no known bio-effects and as it is used routinely in many centres and appears regularly in the media, recruits have prior knowledge of a technique that does not stimulate anxiety.

3D data volumes can now be acquired, manipulated and navigated through to create more familiar image planes, aiding diagnosis or enabling the measurement 
of previously unseen structures. Used prudently, ultrasound is an invaluable research and diagnostic tool. It is currently considered that $3 \mathrm{D}$ and $4 \mathrm{D}$ ultrasound imaging pose no greater hazard to the growing fetus than conventional 2D ultrasound and potentially decrease ultrasound exposure (13). In the obstetric setting, 3D ultrasound use falls broadly into three categories: 1) diagnosis or confirmation of fetal abnormalities of soft tissue structures, such as facial abnormalities, internal organs, placenta or umbilical cord (14-17); 2) diagnosis or confirmation of skeletal dysplasias (18-23); 3) development of organ volume techniques for constructing centile charts in given populations (24-37) and comparison of the reproducibility of $3 \mathrm{D}$ and conventional 2D ultrasound (38-40). There have additionally been a number of publications focussing on specific bony structures, such as imaging of developing fontanelles (41), rib anomalies (23), detection of hard palate anomalies (42), examination of the association between chromosomal aberration and absent or partial nasal bones (43) and sphenoid bone development (44). However, imaging dense bone using ultrasound is fraught with problems resulting in image degradation, signal drop-out, shadowing, scattering of the sound waves, flare and loss of boundary in the image. Furthermore, publications addressing fetal bone imaging per se have been few and little is mentioned of the challenges associated with this type of imaging.

Notably the first paper to describe a technique using 3D ultrasound to evaluate long bone volume was by Chang et al in Taiwan (27); difficulties and limitations were not, however, reported or evaluated and the validity of using ultrasound to examine skeletal shape has not yet been fully addressed. Here, we describe our experiences evaluating $3 \mathrm{D}$ ultrasound to assess fetal femoral size and development, including reproducibility studies, and assessment of its value in deriving additional measurement parameters for use in cohort studies.

Epidemiological research carried out recently in Southampton has highlighted the need to devise techniques for accurate and reproducible measurements of fetal skeletal size, growth and development $(45,46)$. Ultrasound has traditionally been applied to the investigation of soft tissues and does not naturally lend itself to visualising bone, due to its dense nature. There is little literature on ultrasound imaging of fetal bone as computerised tomography and magnetic resonance imaging lead the way in definitive skeletal assessment. Developments in 3D ultrasound suggested, however, that it might be feasible to develop techniques to assess fetal bone development, and we have focused on studies of the fetal femur in a large cohort of pregnant women. The fetal femur was the focus on interest for several reasons. Firstly, it is an easy bone to locate and repeatedly assess in the same plane. It has a characteristic appearance and might be an indicator of the development of other skeletal structures. Secondly, femur length is routinely used to assess gestational age, or as a soft marker for chromosomal aberrations, and as such is a measurement that is well-documented $(47,48)$. However, length alone is a crude measure of development and data on the volume, cross-sectional area, and lateral or transverse diameters of the femur may all add useful information on bone growth and development. Long bones, and particularly the femora, are the most rapidly growing bones of the fetal skeleton, and may be particularly sensitive to environmental influences (49).

The aims of our research were to firstly assess whether 3D ultrasound could adequately visualise and consistently quantify fetal femoral development. Secondly, we attempted to devise novel measurements, to supplement 2D measurement of femur length. These measurements could then be used in epidemiological studies examining fetal skeletal development.

\section{SUBJECTS AND METHODS}

The study was undertaken in participants from the Southampton Women's Survey (SWS), run by the MRC Epidemiology Resource Centre, University of Southampton, UK. The SWS is a population-based study of young women, which includes data on maternal health, diet and lifestyle factors before and during pregnancy (50). Between 1998 and 2002, 12,583 nonpregnant women aged 20 to 34 were interviewed regarding their general health, diet, activity and lifestyle, and gave written consent for their general practitioner to contact the SWS team if they subsequently became pregnant. They were also asked to contact the SWS team directly if they became pregnant. Women registered with a sub-set of general practitioners were invited to take part in an additional study involving neonatal dual-energy $\mathrm{x}$-ray absorptiometry to assess bone density, and femoral ultrasound was performed in this group of subjects.

Women taking part in the SWS pregnancy phase were offered ultrasound scans in the SWS Ultrasound Unit at 11, 19 and 34 weeks' gestation, with an additional early dating scan if the woman's menstrual dates were uncertain. Gestational age was routinely derived from menstrual dates, then confirmed or adjusted at the earliest pregnancy ultrasound data. At each scan, a qualified sonographer (PM) took comprehensive biometric measurements of the fetus and a volume of the uppermost fetal thigh was acquired for later analysis. Between October 2002 and December 2005, 517 participants with singleton uncomplicated pregnancies, where no obvious fetal anomaly or maternal disease had been identified, had fetal thigh volumes collected at their 19 and 34 week scans. All women gave written informed consent before their scans. Ethics approval for the survey and the use of data collected was granted by the Local Research Ethics Committee.

The technique used for this study essentially followed the manufacturer's specification for volume acquisition, which has been used extensively by researchers for fetal organ studies $(24-35,40,51)$. The 


\section{Direction of ultrasound}

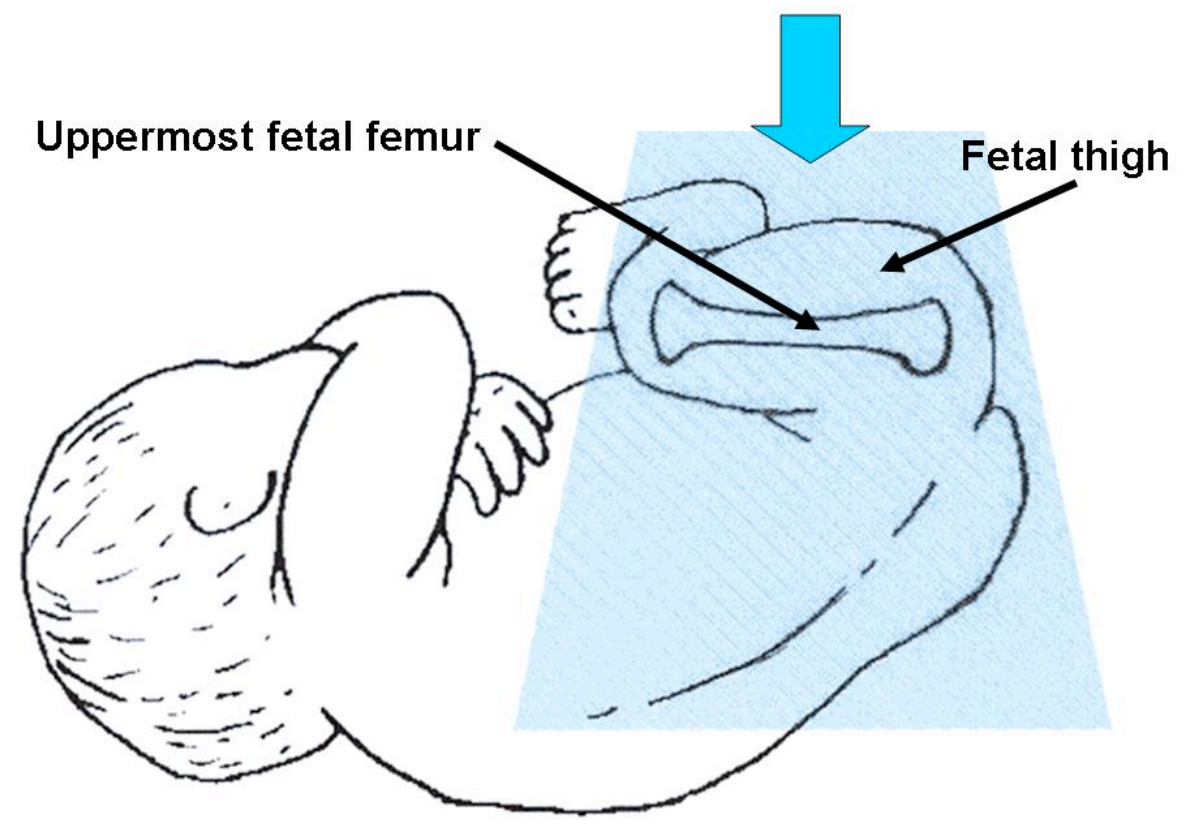

Figure 1. Diagrammatic representation of fetal position in utero relative to the ultrasound beam being directed onto the lateral border of the uppermost fetal femur.

ultrasound scans were performed on a KretzGE Voluson $730 \AA$ system (Kretztechnik AG, Zipf, Austria), which utilises a mechanical 'sweep' system to acquire volume data and produces high resolution images necessary for imaging small structures. The system has a broadband electronic curved-array transducer with a frequency range of 4-8 $\mathrm{MHz}$ and a controllable scan angle for the $3 \mathrm{D}$ sweep from $15^{\circ}$ to $75^{\circ}$ for volume acquisition. The 3D multi-element transducer allows several focal zones to be activated, for optimal resolution at variable depths within the image. To acquire the thigh volume the transducer is positioned over the lateral aspect of the fetal femur, shown in the usual position for femur length measurement (Figure 1). At the press of a key, the 3D function is switched on and the mechanical sweep motor drives the scan-head within the housing through an arc, pulsing ultrasound waves into the subject and receiving the returning echoes between the pulses, as it passes, allowing a 3D volume data set to be acquired and stored for future measurement. The time taken for each sweep can be varied between 1 and 9 seconds to suit the resting state of the fetus. After a few seconds, the A, B and C scan planes are displayed synoptically on the screen, reconstructed from the acquired volume (Figure 2). From these views the relationships of each structure can be easily identified.

Measurements for this study were made offline using the volume data sets viewed in the 3-plane format shown in Figure 2. Images were adjusted for resolution, brightness, contrast and zoom, before each plane was straightened or rotated into the optimal plane for analysis. This aspect is a fundamental function of 3D ultrasound, but if excessive adjustment is made, the resulting reconstruction of the image reduces the accuracy of any measurements taken. Thus standardisation of technique was paramount, an aspect which has only recently been fully addressed by international ultrasound users (52).

Using the planes created by the 3D system, views of the femur previously inaccessible by $2 \mathrm{D}$ ultrasound could be distinguished. A core set of measurements of the femur were then devised utilising the image. In addition to femur length (a linear measurement of femur diaphysis), femur volume (using the manufacturer's multi-plane technique) and cross-sectional area of the proximal, mid-shaft and distal metaphyseal ends (by viewing the femoral shaft in the transverse B plane) were devised (Figure 3), as the multi-plane technique allowed identification of the metaphyseal ends of the femoral shaft.

To assess the operator variability and betweensubject variation, triplets of all measurements were taken from the stored volumes. In practice all of the volume acquisitions and measurement made on the stored volumes were performed by one operator (PM). To assess intra-operator variation in measurement technique, 10 subjects were measured again after a 2week interval.

Statistical analysis was performed using Stata Statistical Software Release 10, 2008, Stata Corporation, College Station, Texas, USA. We used Pearson's correlation coefficients to show the strength of observed associations and their statistical significance. T-tests 


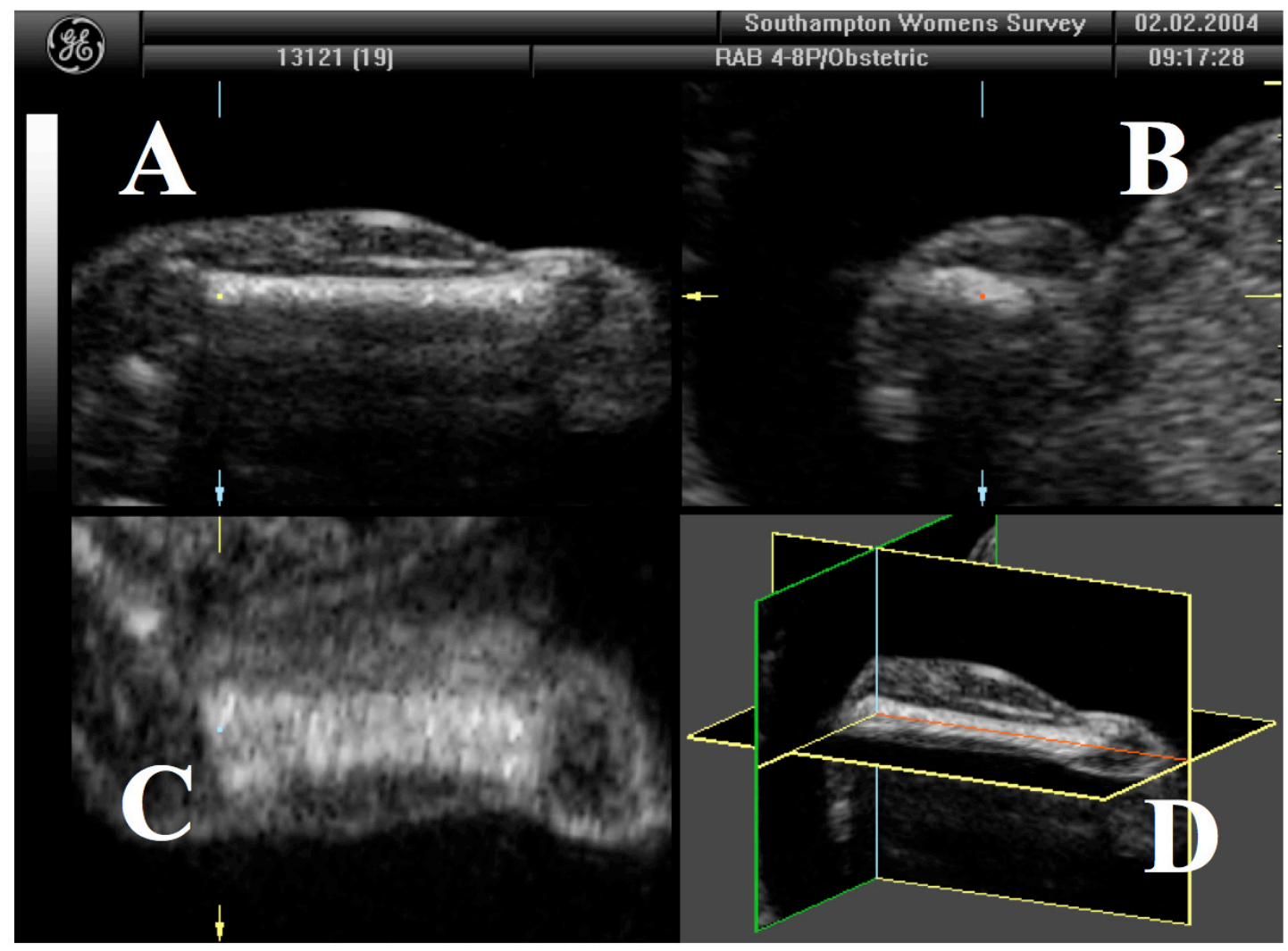

Figure 2. Planes A, B and C showing a 19-week fetal thigh. A; conventional 2D longitudinal plane, B; transverse plane orthogonal to A and C; reconstructed horizontal plane. D shows the orientation of all 3 planes. The femur is a white linear feature within the thigh tissues.
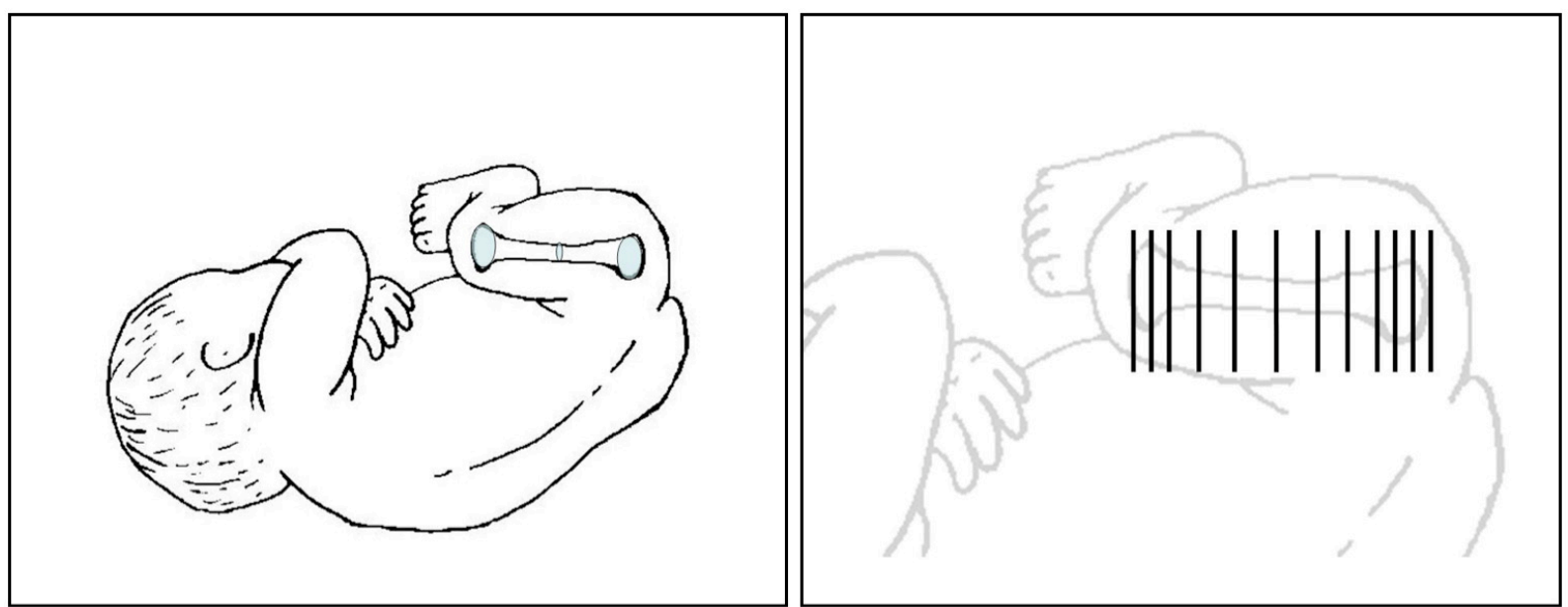

Figure 3. Left-hand panel shows the levels where femur cross-sectional areas were measured. Right-hand panel shows the series where cross-sectional areas were measured to create a femur volume.

were used to examine any gender differences in femoral size and growth velocity. To examine intraoperator and between subject variability, we calculated coefficients of variation, expressed as a percentage, using Martin Bland's root mean square method. Since scan measurements were not all taken at exactly 19 or 34 weeks gestation, we used a regression method to correct for gestational age.

\section{RESULTS}

At 19 weeks calliper placement on the margins of the fetal femur was less problematic than at 34 weeks, when shadowing and flare resulting from the greater bone mineral density rendered the boundaries less distinct in appearance and made calliper placement more subjective. This was particularly noticeable when the 
Table 1. Intra-operator variability and between-subject variation. The range* and median* values relate to the sum of the absolute difference between triplicate measurements and their mean. The coefficient of variation $\left(\mathrm{CV}^{* *}\right.$, expressed as a percentage) was calculated using Martin Bland's root mean square method. ICC is the inter-class correlation between intra-operator variability and between-subject variation values.

\begin{tabular}{|c|c|c|c|c|c|c|c|}
\hline & \multicolumn{3}{|c|}{ Intra-operator variability } & \multicolumn{3}{|c|}{ Between-subject variation } & \multirow[b]{2}{*}{ ICC } \\
\hline & range* & median* & $\operatorname{SD}(C V * *)$ & range & mean & SD (CV) & \\
\hline & \multicolumn{7}{|c|}{19 weeks } \\
\hline Femur length $(\mathrm{cm})$ & $0-0.153$ & 0.027 & $0.017(0.6 \%)$ & $2.51-3.80$ & 3.05 & $0.221(7.2 \%)$ & 0.98 \\
\hline Distal CSA $\left(\mathrm{cm}^{2}\right)$ & $0-0.093$ & 0.010 & $0.020(4.4 \%)$ & $0.117-0.430$ & 0.24 & $0.091(21.8 \%)$ & 0.65 \\
\hline \multirow[t]{2}{*}{ Femur volume $\left(\mathrm{cm}^{3}\right)$} & $0-0.107$ & 0.033 & $0.017(3.4 \%)$ & $0.240-0.907$ & 0.52 & $0.103(19.9 \%)$ & 0.68 \\
\hline & \multicolumn{7}{|c|}{34 weeks } \\
\hline Femur length $(\mathrm{cm})$ & $0-0.233$ & 0.033 & $0.023(0.4 \%)$ & $5.68-7.21$ & 6.44 & $0.284(4.4 \%)$ & 0.98 \\
\hline Distal CSA $\left(\mathrm{cm}^{2}\right)$ & $0-0.220$ & 0.040 & $0.025(3.2 \%)$ & $0.410-1.66$ & 0.80 & $0.189(23.7 \%)$ & 0.85 \\
\hline Femur volume $\left(\mathrm{cm}^{3}\right)$ & $0-0.493$ & 0.073 & $0.048(1.7 \%)$ & $1.71-4.26$ & 2.86 & $0.519(18.2 \%)$ & 0.98 \\
\hline
\end{tabular}

structures being measured were those displayed on planes that had been adjusted after volume acquisition.

At this stage intra-operator variability was examined for the different modes in which the measurements were taken. In essence, simple linear measurements such as femur length are more easily achievable and reproducible than traced measures such as the crosssectional areas of the femoral shaft. Volume measurements are a composite of traced dimensions and as such are subject to the greatest degree of error. Table 1 shows that the intra-operator variability in femur length measurements at 19 weeks was $0.6 \%$ and $0.4 \%$ at 34 weeks. The intra-operator variability in traced measurements of distal cross-sectional area was $4.4 \%$ at 19 weeks and $3.2 \%$ at 34 weeks, showing greater measurement variability within a more complex technique. Intra-operator variability in femur volume measurements at 19 and 34 weeks were $3.4 \%$ and $1.7 \%$, respectively, over the triplets taken.

Between-subject variation was also explored in order to assess the biological variability between fetuses, as opposed to measurement variation. The betweensubject variation in fetal femur length at 19 weeks was $7.2 \%$. Between-subject variation for distal crosssectional area was $19.6 \%$ at 19 weeks and $19.9 \%$ for femur volume. These results show a wide range of variation between subjects, which is substantially greater than the intra-operator variability. This suggests that these measurements are reproducible with little operator-variability and provide a sensitive method of demonstrating differences between subjects.

The summary scan data in Table 2 shows the distributions of core measurements taken at scan from stored thigh volumes at both 19 and 34 weeks. Each measurement was taken 3 times and the mean value used in the analyses. These data were then used to determine if the measures differed by gender. Table 2 shows that length and cross-sectional areas of femoral dimensions are similar in both sexes. However, at 19 weeks there is a significant difference in femur volume
Table 2. Summary measurement data for the entire group at both 19 and 34 weeks gestation and t-test values to show gender differences.

\begin{tabular}{|c|c|c|c|c|c|c|}
\hline \multicolumn{7}{|c|}{ Summary scan data } \\
\hline \multirow{2}{*}{\multicolumn{2}{|c|}{19 weeks }} & \multirow{3}{*}{$\frac{\mathrm{n}}{248}$} & \multirow{3}{*}{$\frac{\text { mean }}{0.10}$} & \multirow{3}{*}{$\begin{array}{c}\text { SD } \\
0.49\end{array}$} & \multicolumn{2}{|c|}{ unpaired t-test } \\
\hline & & & & & $\mathrm{t}$ & $\mathrm{p}$ \\
\hline \multirow{3}{*}{$\begin{array}{l}\text { Femur volume } \\
\left(\mathrm{cm}^{3}\right)\end{array}$} & boys & & & & \multirow{3}{*}{2.55} & \multirow{3}{*}{0.01} \\
\hline & girls & 236 & 0.09 & 0.46 & & \\
\hline & both & 484 & 0.10 & 0.48 & & \\
\hline \multirow{3}{*}{$\begin{array}{l}\text { Femur length } \\
(\mathrm{cm})\end{array}$} & boys & 261 & 0.20 & 2.92 & \multirow{3}{*}{0.83} & \multirow{3}{*}{0.41} \\
\hline & girls & 247 & 0.20 & 2.91 & & \\
\hline & both & 508 & 0.20 & 2.92 & & \\
\hline \multirow{3}{*}{$\begin{array}{l}\text { Proximal CSA } \\
\left(\mathrm{cm}^{2}\right)\end{array}$} & boys & 252 & 0.06 & 0.27 & \multirow{3}{*}{1.20} & \multirow{3}{*}{0.23} \\
\hline & girls & 236 & 0.06 & 0.26 & & \\
\hline & both & 488 & 0.06 & 0.27 & & \\
\hline \multirow{3}{*}{$\begin{array}{l}\text { Mid-shaft CSA } \\
\left(\mathrm{cm}^{2}\right)\end{array}$} & boys & 255 & 0.03 & 0.13 & \multirow{3}{*}{0.80} & \multirow{3}{*}{0.42} \\
\hline & girls & 245 & 0.03 & 0.13 & & \\
\hline & both & 500 & 0.03 & 0.13 & & \\
\hline \multirow{3}{*}{$\begin{array}{l}\text { Distal CSA } \\
\left(\mathrm{cm}^{2}\right)\end{array}$} & boys & 244 & 0.05 & 0.23 & \multirow{3}{*}{1.69} & \multirow{3}{*}{0.09} \\
\hline & girls & 235 & 0.05 & 0.22 & & \\
\hline & both & 479 & 0.05 & 0.23 & & \\
\hline \multicolumn{7}{|c|}{34 weeks } \\
\hline \multirow{3}{*}{$\begin{array}{l}\text { Femur volume } \\
\left(\mathrm{cm}^{3}\right)\end{array}$} & boys & 247 & 0.52 & 2.84 & \multirow{3}{*}{1.84} & \multirow{3}{*}{0.07} \\
\hline & girls & 236 & 0.51 & 2.75 & & \\
\hline & both & 483 & 0.52 & 2.80 & & \\
\hline \multirow{3}{*}{$\begin{array}{l}\text { Femur length } \\
(\mathrm{cm})\end{array}$} & boys & 250 & 0.29 & 6.35 & \multirow{3}{*}{-0.85} & \multirow{3}{*}{0.40} \\
\hline & girls & 241 & 0.27 & 6.37 & & \\
\hline & both & 491 & 0.28 & 6.36 & & \\
\hline \multirow{3}{*}{$\begin{array}{l}\text { Proximal CSA } \\
\left(\mathrm{cm}^{2}\right)\end{array}$} & boys & 240 & 0.21 & 1.03 & & \\
\hline & girls & 230 & 0.20 & 1.00 & 1.63 & 0.11 \\
\hline & both & 470 & 0.21 & 1.01 & & \\
\hline & boys & 249 & 0.07 & 0.34 & & \\
\hline $\begin{array}{l}\left(\mathrm{cm}^{2}\right) \\
\text { (n) }\end{array}$ & girls & 240 & 0.07 & 0.34 & -0.40 & 0.69 \\
\hline & both & 489 & 0.07 & 0.34 & & \\
\hline & boys & 241 & 0.19 & 0.79 & & \\
\hline ( & girls & 227 & 0.18 & 0.77 & 1.25 & 0.21 \\
\hline & both & 468 & 0.19 & 0.78 & & \\
\hline
\end{tabular}


between the sexes $(\mathrm{t}=2.55, \mathrm{p}=0.01)$; the association was weaker at 34 weeks (Table 2). An association between gender and fetal femur volume in early gestation supports research currently underway in Southampton, which has found skeletal growth differences between the sexes in the first trimester (unpublished).

As the measurements were taken at 2 time-points during the pregnancy, a percentage increase was calculated to determine growth velocity between 19 and 34 weeks. The value of femur length, distal cross-sectional area and femur volume at 19 weeks was subtracted from the value at 34 weeks and then divided by the 19 week value to calculate the degree of growth, expressed as a percentage.

Based on the data collected growth velocity was similar in both sexes for length, proximal, mid-shaft and distal cross-sectional area and volume (mean values of $119 \%, 293 \%, 169 \%, 263 \%$ and 509\% respectively). The metaphyseal ends of the femoral shaft increase by $293 \%$ proximally and by $263 \%$ distally. However, the shaft shows less growth velocity as the mean value for both groups was $169 \%$. The proximal and distal ends increase in dimension as they develop into articulations for the hip and knee joints.

\section{DISCUSSION}

This study showed that new measurements of the fetal femur can be made using 3D ultrasound and these novel dimensions can be used to show growth differences between fetuses and variations in femoral shape. The work also highlights some limitations of the technique, where calliper placement can be subjective and hindered by greater bone mineral density at later gestations.

In previous studies the limitations described here have not been reported. Traditionally, ultrasound has been of enormous advantage when imaging soft tissue but bone has always been considered a problematic tissue to visualise due to the very nature of ultrasound waves. However, with optimum equipment adjustment, it was found possible to not only visualise bone shape, but also to derive novel measurements of the femur which may become a useful tool in monitoring maternal influences on fetal bone development or aid the diagnosis of abnormal long bone development. Another limitation of the technique is the time needed to measure each image at the analysis stage. Developments in computing are needed to assist in automation of the measurements, thereby reducing analysis time.

In this study each subject had 3D scan measurements solely at 2 time-points in the pregnancy. However, sufficient data was gathered to derive growth velocity between measurements. The measurement techniques were shown to be sufficiently reproducible for 3D ultrasound to be considered a useful tool for assessing differences in skeletal growth between subjects. Using these additional measurements in epidemiological studies is now possible and work has already begun to use distal metaphyseal cross-sectional area as a measure of splaying of the metaphyseal ends of long bones in the presence of maternal vitamin D insufficiency (Maternal Vitamin D Osteoporosis Study; MAVIDOS). For future use there may be an application to monitor femoral volume during maternal intervention studies aimed at improving fetal bone development. By applying these techniques in cohort studies, further light may be shed on maternal influences on bone health in later life.

\section{ACKNOWLEDGEMENTS}

The authors would like to acknowledge the team which comprise the Southampton Women's Survey and the volunteers and their families for their co-operation.

\section{REFERENCES}

1. Couzin J. Quirks of fetal environment felt decades later. Science 2002; 296: 2167-2169.

2. Harvey N, Cooper C. The developmental origins of osteoporotic fracture. J Br Menopause Soc 2004; 10: 1429.

3. Gluckman PD, Hanson, MA, Cooper C, Thornburg KL. Effect of in utero and early-life conditions on adult health and disease. N Engl J Med 2008; 359: 61-73.

4. Barker DJP. The developmental origins of adult disease. J Am Coll Nutr 2004; 23: 588-595S.

5. Gluckman P, Hanson M. The fetal matrix. Cambridge University Press, UK, 2005.

6. O'Brien KO, Schulman Nathanson M, Mancini J, Witter F. Calcium absorption is significantly higher in adolescents during pregnancy than in the early postpartum period. J Am Coll Nutr 2003; 78: 1188-1193.

7. Gale CR, Martyn CN, Kellingray S, Eastell R, Cooper C. Intrauterine programming of adult body composition. J Clin Endocrinol Metab 2001; 86 (1): 267-272.

8. Antoniades L, MacGregor AJ, Andrew T, Spector TD Association of birth weight with osteoporosis and osteoarthritis in adult twins. Rheumatology 2003; 42: 791-796.

9. Godfrey K, Walker-Bone K, Robinson S, Taylor P, Shore S, Wheeler T, Cooper C. Neonatal bone mass: influence of parental birthweight, maternal smoking, body composition, and activity during pregnancy. JBMR 2001; 16: 1694-1703. 
10. Lanham S, Roberts C, Cooper C, Oreffo ROC. Intrauterine programming of bone. Part 1: alteration of the osteogenic environment. Osteoporos Int 2008; 19: 147-156.

11. Harvey CJ, Pilcher JM, Eckersley RJ, Blomley MJK, Cosgrove DO. Advances in ultrasound. Clin Radiol 2002; 57: 157-177.

12. Nelson TR, Pretorius DH. Three-dimensional imaging. Ultrasound Med Biol 1998; 24 (9): 1243-1270.

13. Hershkovitz R, Sheiner E, Mazor M. Ultrasound in obstetrics: a review of safety. Eur J Obstet Gynecol Reprod Biol 2002; 101: 15-18.

14. Hata T, Aoki S, Hata K, Miyazaki K, Akahane M, Mochizuki T. Three-dimensional ultrasonographic assessments of fetal development. Obstet Gynecol 1998; 91 (2): 218-223.

15. Deurloo K, Spreeuwenberg M, Rekoert-Hollander M, van Vugt J. Reproducibility of 3-dimensional sonographic measurements of fetal and placental volume at gestational ages of 11-18 weeks. J Clin Ultrasound 2007; 35 (3): 125-32.

16. Ramos GA, Ylagan MV, Romine LE, D'Agostini DA, Pretorius DH. Diagnostic evaluation of the fetal face using 3-dimensional ultrasound. Ultrasound $Q$ 2008; 24 (4): 215-223.

17. Lee W, Kirk JS, Shaheen KW, Romero R, Hodges AN, Comstock CH. Fetal cleft lip and palate detection by three-dimensional ultrasonography. Ultrasound Obstet Gynecol 2000; 16 (4): 314-320.

18. Nelson TR, Pretorius DH. Visualization of the fetal thoracic skeleton with three-dimensional sonography: a preliminary report. Am J Roentgenol 1995; 164 (6): 1485-1488.

19. Schild RL, Wallny T, Fimmers R, Hansmann M. The size of the fetal thoraco-lumbar spine: a threedimensional ultrasound study. Ultrasound Obstet Gynecol 2000; 16 (5): 468-472.

20. Garjian KV, Pretorius DH, Budorick NE, Cantrell CJ, Johnson DD, Nelson TR. Fetal skeletal dysplasia: three-dimensional US - initial experience. Radiology 2000; 214 (3): 717-723.

21. Achiron R, Gindes L, Zalel Y, Lipitz S, Weisz B. Three- and four-dimensional ultrasound; new methods for evaluating fetal thoracic anomalies. Ultrasound Obstet Gynecol 2008; 32: 36-43.

22. Kurjak A, Miskovic B, Andonotopo W, Stanojevic M, Azumendi G, Vrcic H. How useful is 3D and 4D ultrasound in perinatal medicine? J Perinat Med 2007; 35 (1): 10-27.

23. Gindes L, Benoit B, Pretorius DH, Achiron R. Abnormal number of fetal ribs on 3-dimensional ultrasonography; associated anomalies and outcomes in 75 fetuses. J Ultrasound Med 2008; 27: 1263-1271.

24. Chang $\mathrm{CH}$, Chang FM, Yu CH, Ko HC, Chen HY. Three-dimensional ultrasound in the assessment of the fetal cerebellar and antero-posterior diameters. Ultrasound Med Biol 2000; 26; 175-182.

25. Chang $\mathrm{CH}$, Chang FM, Yu CH, Ko HC, Chen HY. Assessment of fetal cerebellar volume using threedimensional ultrasound. Ultrasound Med Biol 2000; 26 (6): 981-988.

26. Chang $\mathrm{CH}$, Yu CH, Chang FM, Ko HC, Chen HY. Assessment of fetal adrenal gland volume using threedimensional ultrasound. Ultrasound Med Biol 2002; 27: 1383-1387.

27. Chang $\mathrm{CH}$, Yu CH, Chang FM, Ko HC, Chen HY. Assessment of normal fetal upper arm volume by threedimensional ultrasound. Ultrasound Med Biol 2002; 27: 859-863.

28. Chang $\mathrm{CH}$, Yu CH, Chang FM, Ko HC, Chen HY. The assessment of normal fetal brain volume by 3-D ultrasound. Ultrasound Med Biol 2003; 29 (9): 1267-1272.

29. Chang $\mathrm{CH}$, Yu CH, Chang FM, Ko HC, Chen HY. The assessment of normal fetal liver volume by threedimensional ultrasound. Ultrasound Med Biol 2003; 29: 1123-1129.

30. Chang $\mathrm{CH}, \mathrm{Yu} \mathrm{CH}$, Ko HC, Chang FM, Chen HY. Prenatal assessment of normal fetal humerus volume by three-dimensional ultrasound. Ultrasound Med Biol 2003; 29 (12): 1675-1680.

31. Chang $\mathrm{CH}$, Yu CH, Chang FM, Ko HC, Chen HY. Three-dimensional ultrasound in the assessment of normal fetal thigh volume. Ultrasound Med Biol 2003; 29: 361-366.

32. Chang FM, Hsu KF, Ko HC, Yao BL, Chang CH, Yu CH, Chen HY. Three dimensional ultrasound assessment of the fetal liver volume in normal pregnancy: A comparison of reproducibility with two-dimensional ultrasound and a search for constant volume. Ultrasound Med Biol 1997; 23: 381-389.

33. Chang FM, Hsu KF, Ko HC, Yao BL, Chang CH, Yu CH, Liang RI, Chen HY. Heart volume assessment by three-dimensional ultrasound. Ultrasound Med Biol 1997; 9: 42-48.

34. Chang FM, Liang RI, Ko HC, Yao BL, Chang CH, Yu CH. Three-dimensional ultrasound-assessed fetal thigh volumetry in predicting birth-weight. Obstet Gynecol 1997; 90: 331-339.

35. Cohen LS, Sankpal R, Endres L. Transabdominal three-dimensional volume imaging of the fetal brain at 1824 weeks' gestation. Int J Gynaecol Obstet 2001; 71: 145-150.

36. Liang RI, Chang FM, Yao BL, Chang $\mathrm{CH}$, Yu CH, Ko HC. Predicting birthweight by the fetal upper-arm volume with use of three-dimensional ultrasonography. AJOG 1997; 177: 632-638.

37. Song TB, Moore TR, Lee JI, Kim YH, Kim EK. Fetal weight prediction by thigh volume measurement with three-dimensional ultrasonography. Obstet Gynecol 2000; 96: 157-161.

38. Hata T, Kuno A, Dai S, Inubashiri E, Hanaoka U, Kennishi K, Yamashiro C, Tanaka H, Yanagihara T. Threedimensional sonographic volume measurement of the fetal spleen. Obstset Gynecol 2007; 33 (5): 600-605. 
39. Bromley B, Shipp TD, Benacerraf B. Assessment of the third-trimester fetus using 3-dimensional volumes: a pilot study. JCU 2007; 35 (5): 231-237.

40. Benacerraf B, Shipp TD, Bromley B. Three-dimensional US of the fetus; volume imaging. Radiology 2006; 238 (3): 988-996.

41. Pretorius DH, Nelson TR. Prenatal visualization of cranial sutures and fontanelles with three-dimensional ultrasonography. J Ultrasound Med 1994; 13 (11): 871-876.

42. Wong HS, Tait J, Pringle KC. Viewing of the soft and the hard palate on routine 3D ultrasound sweep of the fetal face - a feasibility study. Fetal Diagn Ther 2008; 24 (2): 146-154.

43. Rembouskos G, Cicero S, Longo D, Vandecruys H, Nicolaides KH. Assessment of the fetal nasal bone at 1114 weeks of gestation by three-dimensional ultrasound. Ultrasound Obstet Gynecol 2004; 23 (3): 232-236.

44. Levaillant JM, Mabille M. Fetal sphenoid bone: imaging using three-dimensional ultrasound and computed tomography. Ultrasound Obstet Gynecol 2008; 31: 229-231.

45. Cole Z, Gale C, Javaid M, Robinson S, Law C, Boucher B, Crozier S, Godfrey K, Dennison E, Cooper C. Maternal dietary patterns during pregnancy and childhood bone mass; a longitudinal study. J Bone Miner Res 2008 Dec 2, 2008:10.1359/jbmr.081212 (Epub ahead of print).

46. Gale CR, Robinson SM, Harvey NC, Javaid MK, Jiang B, Martyn CN, Godfrey KM, Cooper C, Princess Anne Hospital Study Group. Maternal vitamin D status during pregnancy and child outcomes. Eur J Clin Nutr 2008; 62 (1): 68-77.

47. Chitty LS, Altman DG. Charts of fetal size: limb bones. Br J Obstet Gynaecol 2002; 109: 919-929.

48. Honarvar M, Allahyari M, Dehbashi S. Assessment of gestational age based on ultrasonic femur length after the first trimester: a simple mathematical correlation between gestational age (GA) and femur length (FL). Int J Gynaecol Obstet 2000; 70 (3): 335-340.

49. Eveleth PB, Tanner JM. Worldwide variation in human growth ( $2^{\text {nd }}$ edition). Cambridge University Press, UK, 1990

50. Inskip HM, Godfrey KM, Robinson SM, Law CM, Barker DJ, Cooper C, SWS Study Group. Cohort profile: the Southampton Women's Survey. Int J Epidemiol 2006; 35 (1): 42-48.

51. Roelfsema NM, Hop WC, Boito SM, Wladimiroff JW. Three-dimensional sonographic measurement of normal fetal brain volume during the second half of pregnancy. Am J Obstet Gynecol 2004; 190 (1): 275-280.

52. Merz E, Benoit B, Blaas HG, Baba K, Kratochwil A, Nelson T, Pretorius D, Jurkovic D, Chang FM, Lee A, ISUOG Focus Group. Standarization of three-dimensional images in obstetrics and gynecology: consensus statement. Ultrasound Obstet Gynecol 2007; 29: 697-703. 